\title{
Os ambientes de aprendizagem na época da hipermídia e da Educação a distância
}

\section{George França}

\author{
Professor da Fundação Universidade do Tocantins \\ UNITINS - Doutor em Educação: Currículo - \\ Pontifícia Universidade Católica - São Paulo, \\ Brasil
}

O presente artigo discute os ambientes de aprendizagem na época da hipermídia e da Educação a Distância. Para isso, contextualiza a questão das tecnologias e seus impactos na Educação. Apresenta as inserções da hipermídia e de suas aplicabilidades dentro deste cenário e descreve os Ambientes Hipermidiáticos, as suas funções e correlações nos processos de design instrucional. Faz uma reflexão contemporânea sobre a EaD, percebendo basicamente a inserção das linguagens e tecnologias $e$ suas conexões com o campo da aprendizagem.

Palavras-chaves:Hipermídia;EaD;Design;Aprendizagem.

\section{The learning environments in the era of hypermedia and distance education.}

This article discusses the learning environments in the era of hypermedia and Distance Education. For this, the issue of technology and its impact on education is contextualized. It presents the insertion of hypermedia and its applicability in this scenario and describes the hipermediatic environments, functions and correlations in the processes of instructional design. A contemporary reflection on distance education is brought about, having, as the basis, the integration of technologies and languages and its connections with the field of learning.

Keywords: Hypermedia, Distance Learning, Design, Learning

Recebido em 10.12.2008 Aceito em 12.03.2009 


\section{Contextos sociais: conhecimento, tecnologia e ensino- aprendizagem}

Os primeiros anos deste século XXI consolidaram os conceitos de rede, ciberespaço ${ }^{1}$ e hipermídia como linguagem. De maneira direta, tais elementos tornaram-se alavancas de um processo crescente das novas formas de trabalho, da economia e do pensar e agir contemporâneos. As estruturas organizacionais produtivas e financeiras das empresas e das universidades moldaram-se, visivelmente, de acordo com este fenômeno global, estabelecendo novas ordens e parâmetros mercadológicos que impulsionaram uma cultura educacional emergente, globalizada e, muitas vezes, idealizada e modelada pelo mercado e pelos ditames do capital.

Levando-se em consideração todas as questões históricas e estruturais relacionadas à Educação e à Tecnologia, a discussão contemporânea ganha uma outra visão, pois percebemos que alguns modelos e valores tão tradicionais nas universidades e nas instituições de ensino começam a ficar obsoletos. Do mesmo modo, os estilos de trabalho - e, até mesmo, a compreensão dos processos de produção do conhecimento e da utilização das tecnologias - adquirem outros sentidos.

Neste contexto, observamos com mais atenção as relações entre conhecimento, tecnologia e ensino-aprendizagem - principalmente por ser este o momento de primazia da hipermídia, da globalização e da informação. Torna-se, assim, um grande desafio para os educadores perceberem que as relações que se conectam à aprendizagem transcendem as salas de aula convencionais e se aproximam, cada vez mais, das experiências individuais vividas na diversidade das linguagens tecnológicas, e também daquilo que chamamos de grupos sociais.

A Educação, especialmente à distância, pensada dentro deste cenário, passa a ser uma temática bastante contemporânea, na qual, em meio a tantas outras, se sobressaem as seguintes questões:

- Que tipo de Educação a Distância (EaD) se quer?

- Quais seriam os ambientes de aprendizagem adequados?

- Esses ambientes possibilitam aos alunos uma aprendizagem dinâmica, significativa e possível de ser avaliada?

Essas reflexões nos trazem fortes impactos na forma de perceber os processos educacionais, e já sabemos não ser possível fazer EaD apenas disponibilizando conteúdos e tecnologia aos alunos e professores, como se pensou anteriormente na "época industrial" da EaD. Além disso, compreendemos que somente interfaces/ferramentas de autoria e de

Fernandes (2006) afirma que a palavra "ciberespaço" foi criada pelo escritor de ficção científica norte-americano William Gibson, em seu livro Neuromancer (1984). O ciberespaço, na concepção de Gibson, é diferente da Web que temos hoje, particularmente com relação aos dispositivos de hardware: o usuário gibsoniano precisava se conectar a um console e penetrar numa realidade virtual. Após a criação da interface gráfica da Internet, no começo da década de 1990, o conceito foi ampliado para conter também dentro de si o espaço virtual da World Wide Web. 
publicação de conteúdo também não bastam, uma vez que o trabalho de desenvolvimento de um curso ou disciplina engloba uma equipe, composta por diferentes profissionais de áreas distintas que se complementam, tais como pedagogos, designers, redatores, programadores e outros, caracterizando a interdisciplinaridade necessária à resolução de problemas dentro desses novos paradigmas.

Por tudo isso, salientamos a importância de se compreender os ambientes hipermidiáticos de aprendizagem e suas utilizações, não meramente como demonstração de um aparato tecnológico, mas como uma outra maneira de assimilar e representar as novas formas didáticas e educacionais da contemporaneidade que as tecnologias e seus contornos apresentam.

\section{Consolidação como linguagem}

Desde a Arpanet $^{2}$ até os mais atuais sistemas de $W e b$, a linguagem do ciberespaço teceu um caminho de amplos sentidos e múltiplas possibilidades trazidas por um conjunto de tecnologias, culturas e filosofias que, vinculadas a discussões político-econômicas e estruturais, moldaram o comportamento comunicacional de uma geração inteira. Isso impactou profundamente as formas de relacionamento e de profissionalização, e mesmo as perspectivas do mundo em que vivemos.

No início deste século, Castells (2003) e Lévy (2001) já refletiam sobre as conseqüências de um pensar mais global representado pela Internet, que incidiria sobre grande parte das nossas vidas. A afirmação e a expansão da Internet, conseqüentemente, comporiam um novo capítulo de nossa história mundial, representado pela intervenção de uma nova cibercultura e de padrões mercadológicos aptos a moldar nosso pensar e agir, modificando, substancialmente, nosso comportamento.

Assim, como afirma Castells (2003, p. 7), nas páginas iniciais de uma de suas obras,

A internet é o tecido de nossas vidas. Se a tecnologia da informação é hoje o que a eletricidade foi na Era Industrial em nossa época, a internet poderia ser equiparada tanto a uma rede elétrica, quanto ao motor elétrico, em razão de sua capacidade de distribuir a força da informação por todo o domínio da atividade humana.

O autor ressalta, ainda, e especialmente, as especificidades de sua cultura:

2 Advanced Research Projects Agency Network - ARPANET: Rede de longa distância criada nos EUA em 1965. 
A cultura da internet é a cultura dos criadores da internet. Por cultura entendo um conjunto de valores e crenças que formam o comportamento; padrões representativos de comportamento geram costumes que são repetidos por instituições bem como por organizações sociais e informais (CASTELLS, 2003, p. 7).

Lévy (2001, p. 130-131), utilizando a música como referencial, também aponta para essa visão globalizante e surpreendente, que demarca a nossa época e as dimensões desse ciberespaço em construção, trazendo em si a marca de uma nova cultura. Segundo ele:

Quando escutamos os japoneses tocando Beethoven, ou os chineses cantando Verdi, não devemos pensar que eles foram seduzidos pela música "ocidental". Essa música não é 'ocidental', é universal, e isso porque ela pode tocar o coração de todos. Da mesma forma, a contribuição dos ritmos africanos ou das sonoridades indianas para a música popular mundial é agora um fato irreversível.

O autor afirma ainda que:

Em algumas gerações, não poderemos mais distinguir muito bem o que vem daqui ou de lá. O que importa? Não é a origem geográfica da música que lhe dá brilho, mas as cadeias vivas e multiplamente ramificadas dos músicos viajantes que a escutam, a dominam, a interpretam e a recriam (LÉVY, 2001, p. 130-131).

Neste cenário, não apenas no campo educacional, mas em toda a sua dimensão espacial/global, a hipermídia passou a ser a linguagem do ciberespaço e da cultura em movimento constante e evolutivo, em que seus valores se reafirmam, pressupondo um mundo de operações, funções e significações diferenciadas, vividas e experienciadas pelas pessoas. Ela possui como anteparo uma série de mídias alocadas num mesmo suporte e apresenta, através dessa união, uma personalidade diferente, repleta de interatividade, caminhos e opções para os seus adeptos e/ou usuários. Dessa forma, compõe-se como um "mix" de linguagens, unindo várias mídias que se complementam, sustentando-se como linguagem híbrida, ou, como reflete Machado (2001, p.146-147):

Hipermídia é (...) uma forma combinatória, permutacional e interativa de multimídia, em que textos, sons e imagens (estáticas e sem movimento) estão ligados entre si por elos probabilísticos e móveis, que podem ser configurados pelos receptores de diferentes maneiras, de modo a compor obras instáveis, em quantidades infinitas. $\mathrm{Na}$ sua forma mais avançada e limítrofe, a hipermídia seria algo assim como um 
texto verbo-audiovisual escrito no eixo do paradigma, ou seja, um texto que já traz dentro de si várias outras possibilidades de leitura e diante do qual se pode escolher dentre várias alternativas de atualização.

No âmbito educacional, a hipermídia e seus ambientes de aprendizagem trouxeram elementos que podem ser facilitadores do processo de aprendizagem; pelo menos é o que se espera, já que os processos tecnológicos tendem a otimizar tempo, o espaço e a compreensão de questões bastante complexas. Por esse motivo, essa retrospectiva nos lembra que os Ambientes Hipermidiáticos de Aprendizagem - AHA encontram-se disponibilizados no ciberespaço e participa diretamente deste cenário, assim como da nova linguagem e das suas características.

Os ambientes hipermidiáticos de aprendizagem possibilitam a combinação de recursos de som, vídeo, textos interconectados e banco de dados, permitindo ao usuário seguir e construir seus próprios percursos, além de reunir alunos e professores de diferentes contextos, bairros, cidades, estados e países.

Os $\mathrm{AHA}^{3}$ são, enfim, entendidos como recursos utilizados para mediar, facilitar e gerir os processos de ensino-aprendizagem em cursos on-line, compostos por um conjunto de ferramentas tecnológicas que, aliadas ao design instrucional de um projeto, proporcionam a possibilidade de distribuição de conteúdo, gerenciamento da informação e outros fatores relacionados às interações gerais de um curso e à produção de conhecimento.

\section{Os Ambientes Hipermidiáticos de Aprendizagem}

De volta aos anos 90, principalmente após o processo de popularização da Internet, muitos ambientes hipermidiáticos foram desenvolvidos, alguns em escalas internacionais, como o WebCT, WebFuse, TopClass, Mallard e Blackboard. Em escalas de menor alcance, porém extremamente representativas, instituições de ensino superior desenvolveram algumas plataformas para suprir suas demandas internas, como a Universidade Federal de Santa Catarina (UFSC), a Universidade do Sul de Santa de Catarina (UNISUL) e a Universidade Virtual Brasileira (UVB), entre outras do mercado corporativo. Atualmente, novos conceitos são apresentados, como os Ambientes livres ${ }^{4}$, ou seja, softwares livres ${ }^{5}$ (código aberto) que apresentam os mesmos recursos e funcionalidades dos softwares proprietários, como por exemplo:

3 As denominações Ambientes Virtuais de Aprendizagem (AVA) ou Ambientes Digitais de Aprendizagem (ADA) correspondem, aqui, a funcionalidades similares. Portanto, ao encontramos os outros conceitos neste texto, correspondem eles ao AHA.

4 Os referidos AHA livres apresentam-se como a grande tendência de uso no mercado atualmente. Isso ocorre por não terem custo ou valor de licença e também por disporem de uma ótima base estrutural, geralmente em PHP.

5 Disponível em: <http://www.softwarelivre.org>, site informativo sobre software livre. Acesso em: 06 mar. 2009. 
a) Moodle (http://moodle.com/);

b) Teleduc (http://teleduc.nied.unicamp.br/teleduc/) e

c) Atutor (http://www.atutor.ca/).

Pelas suas características de desenvolvimento e por suas comunidades, podemos até mesmo pressupor que, em breve, outras soluções serão oferecidas internacionalmente, com o mesmo propósito.

Nos cursos a distância realizados pela Internet, o ambiente hipermidiático de aprendizagem torna-se um ambiente programado, com recursos e interfaces/ferramentas organizados. Essa organização abrange, também, os conteúdos e as atividades disponibilizados aos estudantes pelos professores, o que nos permite afirmar haver uma relação entre o design instrucional e as necessidades de interação dos seus utilizadores.

Todas as ferramentas distribuídas são necessárias para que o docente administre seu planejamento, publicando avisos, atividades, notícias, material de aulas, objetos de aprendizagem, além dos conteúdos necessários a um curso on-line, possibilitando, desse modo, as interações e intervenções entre os vários agentes de socialização nestes ambientes.

Assim, este conjunto de ferramentas é elaborado para servir como guia de uso e de determinação de tarefas, contabilizando três princípios básicos:

a) Primeiro: O aluno tem um roteiro planejado exteriormente, no qual cria largas avenidas a serem seguidas;

b) Segundo: O aluno deve desempenhar atividades que cumpram as finalidades do programa (geralmente motivadoras, luminosas, simuladoras, interativas);

c) Terceiro: O ambiente criado registra, orienta, demanda resultados de percurso e fornece informações sobre o desempenho do aluno aos administradores.

\section{Funções dos ambientes de aprendizagem}

No que diz respeito às suas funções, podemos observar a existência de uma dupla função e finalidade conceitual no $\mathrm{AHA}^{6}$. Algumas derivam do estilo tradicional de educação presencial, junto a tendências comportamentalistas de processo. As que são estruturadas de acordo com as tendências sócio-interacionistas, em contrapartida, nem sempre se encontram coerentes com seu discurso.

As primeiras, de certo modo, preocupam-se mais diretamente com os processos, controles, alterações de comportamento, monitoramentos e resultados. As segundas voltam-se às interações e processos de significação e construção de conhecimento que se fazem presentes nas relações entre os agentes. Ambas as derivações são entendidas neste artigo como significativas e importantes, uma vez que podem ser utilizadas no design instrucional de cursos on-line, bem como nos seus planejamentos.

\footnotetext{
${ }^{6}$ Isto porque estão presentes concepções pedagógicas que norteiam as suas funcionalidades.
} 
Em cada ambiente são apresentadas particularidades, de acordo com a abordagem que originou o seu desenvolvimento (tanto conceitual quanto tecnológico). Elas tornam-se visíveis no momento em que os cursos são colocados em prática: pouca ou muita flexibilidade, facilidade ou dificuldade de visualização de dados, etc.

Mesmo seguindo tendências semelhantes com referência às ferramentas empregadas, os AHA diferenciam-se na arquitetura gerencial e na interface para o usuário final. Observamos este fato na disposição dos meios assíncronos e síncronos ${ }^{7}$ apresentados através de fóruns, chats, mecanismos para publicação de atividades, bancos de dados e outros, além da possibilidade de criação de textos não lineares.

O ideal é que os ambientes hipermidiáticos de aprendizagem sejam flexíveis e se adaptem aos objetivos últimos do projeto/design. Em nosso entendimento, são espaços planejados para dar condições de alteração de comportamentos e hábitos de trabalho, viabilizar o diálogo, a reflexão e o registro crítico de percursos cognitivos.

Os ambientes hipermidiáticos de aprendizagem devem privilegiar os seguintes aspectos nos projetos de design instrucional:

a) Flexibilidade do design instrucional: compreender a gama de abordagens e concepções de ensino-aprendizagem em jogo no desenvolvimento de cursos on-line;

b) Gerenciamento de usuários: perceber a existência de usuários com perfis, determinações e acessos diferenciados, que geram funções e ações distintas no uso do ambiente;

c) Controle de atividades: permitir ao aluno gerenciar as atividades e facilitar aos professores e outros agentes a possibilidade de intervenções. Permitir aos alunos uma navegação autônoma;

d) Mecanismos de retorno: gerar mecanismos de retorno frente às ações de seus usuários, sejam atividades específicas, retornos na navegação ou acesso, mesmo que em forma de relatórios;

e) Formas de produção de atividades: oferecer meios e mecanismos de produção e desenvolvimento de atividades múltiplas, que ofereçam aos elaboradores um menu de opções correspondentes à sua proposta pedagógica;

f) Back-up de arquivos das produções colaborativas e individuais de um curso on-line: dispor de mecanismos que depositem, em lugar seguro, os registros dos processos desenvolvidos durante o período de existência de um curso;

g) Bons mecanismos de acessibilidade e usabilidade para os seus usuários: possibilitar uma navegação de fácil compreensão para o usuário, pois o ambiente é a interface que favorece o

\footnotetext{
${ }^{7}$ Os meios síncronos são aqueles que permitem ao usuário uma comunicação em tempo real, como ocorre, por exemplo, em ferramentas de bate-papo. Os meios assíncronos trabalham com a comunicação não imediata, como ocorre nos fóruns de discussão e até mesmo nos e-mails.
} 
processo de aprendizagem. Ele precisa ser compatível com a experiência e o repertório dos seus usuários;

h) Mecanismos de colaboração: dispor de mecanismos que possibilitem a construção de atividades colaborativas e de integração dos diversos agentes envolvidos no processo de ensino-aprendizagem;

i) Interfaces de comunicação e criação de comunidades: os ambientes devem possibilitar a criação de comunidades e de ações conjuntas entre os usuários, quer sejam para fins específicos de uma disciplina ou não;

j) Mecanismos de autogerenciamento dos eventos de aprendizagem: os ambientes devem dispor de interfaces que possibilitem autonomia na aprendizagem.

Esses aspectos descritos fazem parte de uma escala de valores, ou mesmo de ações, que podem/devem estar presentes nas características funcionais dos ambientes de aprendizagem; mas, obviamente, são os aspectos humanos presentes nas formas de mediação que irão proporcionar os entendimentos sobre as vias de acesso para a produção de conhecimento, por isso a importância de se relacionar a essa discussão a necessidade de se perceber o design instrucional enquanto articulador de possibilidades de aprendizagem.

É também importante perceber que outros elementos se tornam relevantes neste cenário, como, por exemplo, a observação de que boa parte dos processos educacionais com utilização da Internet produz um grande volume de informação que deverá ser distribuído para um elevado número de alunos/usuários de um dado sistema. Os AHA caracterizam-se, assim, pela forma como simplificam o gerenciamento, a distribuição e a atualização dos conteúdos usados, permitindo o compartilhamento das informações. Desse modo, podemos afirmar que eles são recursos utilizados para mediar e facilitar os processos de ensino-aprendizagem em cursos on-line, compondo-se de um conjunto de mecanismos hipermidiáticos, que devem estar em sintonia com a proposta afirmada em um dado momento.

\section{Algumas considerações e conclusões}

Vimos nesta reflexão que os ambientes de aprendizagem na época da hipermídia e da Educação a Distância representam, não só mecanismos tecnológicos, mas dispositivos que possibilitam a produção do conhecimento. Isso se dá não pelo mero uso da tecnologia de maneira despropositada ou casual, mas pelas suas articulações com o design instrucional. Na verdade, precisamos perceber que todos os elementos deste processo estão conectados, fazem parte de um mesmo sistema. Por isso a importância de se compreender o contexto da EaD e dos ambientes de aprendizagem. E, ainda neste sentido, nos perguntamos sobre o tipo de EaD que queremos construir e mesmo quais os tipos de ambientes que queremos usar. 
Desta forma, não devemos perder de vista que toda esta reflexão trata de processos educacionais relacionados não às meras tecnologias que se auto-atualizam no tempo, mas à dimensão humana que se sobressai a esse tempo/espaço. Referimo-nos às tecnologias e suas linguagens como fontes de humanização e de democratização de todas as formas de ensino. A hipermídia, aqui representada pelos seus ambientes de aprendizagem, traz os reflexos deste pensar ideológico, fazendo com que refletir sobre a Educação frente à tecnologia e às misturas de linguagens que a acompanham torne-se algo complexo em sua mais ampla dimensão.

Nossa reflexão requer, portanto, uma refinada compreensão da figura histórica do Homem, seus processos de aprender, ensinar e, principalmente, relacionar-se com um mundo transformado tecnologicamente, mas que ainda precisa ser mais honesto, justo, fraterno e igualitário.

A Educação é, inegavelmente, uma porta para esta nova humanização.

\section{Referências e outros documentos consultados}

CASTELLS, M. A galáxia da internet: reflexões sobre a internet, os negócios e a sociedade. Rio de Janeiro: Jorge Zahar, 2003.

FERNANDES, F. Imaginário: William Gibson, criador da Cibercultura. São Paulo: Anhembi Morumbi, 2006.

GIBSON, W. Neuromancer. [São Paulo]: Aleph, 1984.

LÉVY, P. A conexão planetária: o mercado, o ciberespaço, a consciência. São Paulo: Editora 34, 2001.

MACHADO, A. O quarto iconoclasmo (e outros ensaios hereges). Rio de Janeiro: Contracapa, 2001.

\section{Bibliografia}

ALMEIDA, F. J. Educação e informática: os computadores na escola. São Paulo: Cortez, 1987.

BARBOSA, R. M. (Org.). Ambientes virtuais de aprendizagem. Porto Alegre: Artmed, 2005.

BAUM, W. M. Compreender o behavirismo: comportamento, cultura e evolução. Porto Alegre: Artmed, 2006.

BAUMAN, Z. O mal-estar da pós-modernidade. Rio de Janeiro: Jorge Zahar, 1998.

BURKE, P.; BRIGGS, A. Uma história social da mídia: de Gutenberg à internet. Rio de Janeiro: Zahar, 2004. 
BURKE, P. Uma história social do conhecimento: de Gutenberg a Diderot. Rio de Janeiro: Jorge Zahar, 2003.

DENCKER, A. F. M.; DA VIÁ, S. C. Pesquisa empírica em Ciências Humanas. São Paulo: Futura, 2001.

DOMINGUES, D. (Org.) A arte no século XXI. São Paulo: UNESP, 1997.

FRANÇA, G.; FALCÃO, D.; MOREIRA, M. G. Curso de preparação de professores autores e tutores para EaD. São Paulo: Rede Brasileira de Educação a Distância, 2000.

FRANÇA, G. Curso de preparação de professores autores e tutores para EaD. São Paulo: Rede Brasileira de Educação a Distância, 2000.

. O design instrucional na educação a distância: John Dewey como uma referência metodológica. São Paulo: Esfera, 2007.

GIUSTA, A. S.; FRANCO, I. M. Educação a distância: uma articulação entre a teoria e prática. Belo Horizonte: PUC/MINAS, 2003.

LITWIN, E. (Org.). Tecnologia educacional: política, histórias e propostas. Porto Alegre: Artes Médicas, 1997.

MATURAMA, H. R.; VARELA, F. J. A árvore do conhecimento: as bases biológicas da compreensão humana. São Paulo: Palas/Athena, 2001.

MORAN, J. M.; MASETTO, M.; BEHRENS, M. Novas tecnologias e mediação pedagógica. Campinas, SP: Papirus, 2000. Disponível em: <http://www.eca.usp.br/prof/moran/inov.htm>. Acesso em: 15 mar. 2006.

MOREIRA, M. A. Teorias de aprendizagem. São Paulo: EPU, 1999.

NEVES, A.; CUNHA FILHO, P. C. (Orgs.). Projeto Virtus: educação e interdisciplinaridade no ciberespaço. São Paulo: Anhembi Morumbi/Editora Universitária UFPE, 2000. (Série Universal Virtual).

OLIVEIRA NETTO, A. A. Novas tecnologias \& universidade: da didática tradicionalista à inteligência artificial: desafios e armadilhas. Petrópolis: Vozes, 2005.

PAAS, L. Design educacional. Florianópolis: UFSC/LIED, 2001. Disponível em: <http://www.eps.ufsc.br/disc/tecmc/designedu.html>. Acesso em: 27 nov. 2002.

PALLOF, R. M.; PRATT, K. Construindo comunidades de aprendizagem no ciberespaço: estratégias eficientes para salas de aula on-line. Porto Alegre: Artmed, 2002.

O aluno virtual: um guia para trabalhar com estudantes on-line. Porto Alegre: Artmed, 2005.

PETERS, O. A educação a distância em transição: tendências e desafios. São Leopoldo, RS: UNISINOS, 2002.

Didática do ensino a distância: experiências e estágio da discussão numa visão internacional. São Leopoldo: UNISINOS, 2003. 
SANTAELLA. L. Navegar no ciberespaço: o perfil cognitivo do leitor imersivo. São Paulo: Paulus, 2004.

SIILVA, M. Sala de aula interativa. Rio de Janeiro: Quartet, 2001.

WURMAM, R. S. Ansiedade de informação: como transformar informação em compreensão. São Paulo: Cultura, 1991.

ZABALA, A. Enfoque globalizador e pensamento complexo: uma proposta para o currículo escolar. Porto Alegre: Artmed, 2002. 